\title{
Impact of Type 1 Diabetes Mellitus on the Family is Reduced with the Medical Home, Care Coordination, and Family-Centered Care
}

\section{Citation}

Katz, Michelle L., Lori M. Laffel, James M. Perrin, and Karen Kuhlthau. 2012. "Impact of Type 1 Diabetes Mellitus on the Family Is Reduced with the Medical Home, Care Coordination, and Family-Centered Care." The Journal of Pediatrics 160 (5) (May): 861-867. doi:10.1016/ j.jpeds.2011.10.010.

\section{Published Version}

doi:10.1016/j.jpeds.2011.10.010

\section{Permanent link}

http://nrs.harvard.edu/urn-3:HUL.InstRepos:30207924

\section{Terms of Use}

This article was downloaded from Harvard University's DASH repository, and is made available under the terms and conditions applicable to Other Posted Material, as set forth at http:// nrs.harvard.edu/urn-3:HUL.InstRepos:dash.current.terms-of-use\#LAA

\section{Share Your Story}

The Harvard community has made this article openly available.

Please share how this access benefits you. Submit a story.

Accessibility 


\title{
Impact of Type 1 Diabetes on the Family is Reduced by the Medical Home, Care Coordination and Family Centered Care
}

\author{
Michelle L. Katz, MD, MPH ${ }^{\star}, \dagger$, Lori M. Laffel, MD, MPH ${ }^{\dagger}$, James M. Perrin, MD ${ }^{\star}$, and Karen \\ Kuhlthau, PhD." \\ "Center for Child and Adolescent Health Policy, Massachusetts General Hospital, Boston, MA, \\ 02114
}

†Section on Genetics and Epidemiology, Joslin Diabetes Center, Boston, MA 02215

\section{Abstract}

Objectives-To examine whether the medical home, care coordination, or family-centered care was associated with less impact of type 1 diabetes (T1D) on families' work, finances, time, and school attendance.

Study design-Using the 2005-2006 National Survey of Children with Special Health Care Needs, we compared impacts among children with T1D $(n=583)$, with other special health care needs $(n=39,944)$, and without special health care needs $(n=4,945)$. We modeled the associations of the medical home, care coordination and family-centered care with family impacts in T1D.

Results-In families of children with T1D, 75\% reported a major impact versus $45 \%$ of families of children with special health care needs ( $\mathrm{p}<0.0001)$ and $17 \%$ of families of children without special health care needs $(\mathrm{p}<0.0001)$. In families of children with T1D, 35\% reported restricting work, 38\% reported financial impact, $41 \%$ reported medical expenses $>\$ 1000 /$ year, $24 \%$ reported spending $\geq 11$ hours/week caring or coordination care and $20 \%$ reported $\geq 11$ school absences/year. The medical home, care coordination and family-centered care were associated with less work and financial impacts.

Conclusions-In childhood T1D, most families experience major impacts. Better systems of health care delivery may help families reduce some of these impacts.

The management of diabetes places substantial demands on families and providers. Contemporary diabetes management requires both close collaboration with families who perform day-to-day management tasks and coordination of care between specialists, primary care providers, schools and day care. Given the demands of the management of type 1 diabetes (T1D), families may experience impacts in the areas of work, finances, time and school attendance. The medical home, care coordination, and family-centered care may help families better manage the demands of diabetes care and experience less impact in these areas.

(C) 2011 Mosby, Inc. All rights reserved.

Corresponding author: Michelle L. Katz, MD, michelle.katz@ joslin.harvard.edu, phone 617-309-4633, fax 617-309-2451, address: Joslin Diabetes Center, 1 Joslin Place, Boston, MA 02215.

The authors declare no conflicts of interest.

Publisher's Disclaimer: This is a PDF file of an unedited manuscript that has been accepted for publication. As a service to our customers we are providing this early version of the manuscript. The manuscript will undergo copyediting, typesetting, and review of the resulting proof before it is published in its final citable form. Please note that during the production process errors may be discovered which could affect the content, and all legal disclaimers that apply to the journal pertain. 
The American Academy of Pediatrics defines the medical home as care that is accessible, family-centered, coordinated, comprehensive, continuous, compassionate, and culturally effective(1). In addition to the presence of a medical home, we focused on two aspects of the medical home in particular, coordinated care and family-centered care. The former because of the importance of the multidisciplinary diabetes team involved in treating children with T1D and the latter because of the critical importance of the family in day-to-day diabetes management for children.

The literature describing the work, financial, time and school impacts of T1D for families is limited. Although high out-of-pocket costs were demonstrated over a decade ago (2), the financial impact and out-of-pocket costs for families with T1D has likely changed greatly in the past decade because of substantial changes in diabetes management technologies (3). Studies have demonstrated that T1D places substantial time demands on families for management (4) and that children with T1D miss more school than their peers $(5,6)$, but neither finding has been demonstrated in a large, nationally representative sample of children with T1D. Additionally, whether the medical home is associated with less impacts of T1D on families has not been evaluated to the best of our knowledge.

We hypothesized that families of children with T1D would report more work, financial, time and school impacts than other families with special health care needs and families of children without any special healthcare needs. We further hypothesized that families of children with T1D who reported a medical home, care coordination, or family-centered care would report less family impact than families who did not report these care delivery characteristics.

\section{Methods}

The National Survey of Children with Special Health Care Needs (NSCSHCN) 2005-2006 provided data for this analysis (7). It is a random digit dial survey conducted by the National Center for Health Statistics (NCHS) and sponsored by the Maternal and Child Health Bureau (MCHB) of the Health Resources and Services Administration. Respondents were a knowledgeable parent or guardian who lived with the child. The response rate was $56.1 \%$ among CSHCN and 50.3\% among children without special healthcare needs (7).

CSHCN were identified through a screening instrument (8) as children who experienced one or more health consequence that was expected to last 12 months or more: need for or use of prescription medications; elevated need for or use of medical, mental health, or educational services; functional limitations; need for or use of special therapies; or emotional, developmental or behavioral conditions that require treatment.

We categorized families into three groups: 1) families of children with T1D; 2) families of CSHCN without diabetes; and 3) families of children not selected on the basis of their special health care needs status (referred to as children without special health care needs). Children with T1D were defined by a parent providing an affirmative answer to the following two questions: (1) "To the best of your knowledge, does your child currently have any of the following conditions? Diabetes?" (2) "Does your child use insulin?"(7). Further restriction of this insulin treated population excluded youth with cystic fibrosis, autism, Down Syndrome, mental retardation, cerebral palsy, and muscular dystrophy in order to ensure attribution of the family impact to T1D instead of another severe condition. In the CSHCN group, children with multiple conditions were not excluded.

We examined five markers indicating impact of illness on the family: work restriction, financial impact, high medical expenses, time impact, and school absenteeism. 
The presence of work restriction was determined by an affirmative answer to either of two questions: "Have you or other family members cut down on the hours you work because of your child's health conditions?" or "Have you or other family members stopped working because of your child's health conditions? The presence of financial impact was determined by an affirmative answer to either of two questions: "Have your child's health conditions caused financial problems for your family?" or "Have you needed additional income to cover your child's medical expenses?" High medical expenses were defined by families indicating greater than $\$ 1000$ in expenses to the question "During the past 12 months, would you say that the family paid more than $\$ 5000, \$ 1000$ to $\$ 5000$, or less than $\$ 1000$ for your child's medical care?"

The presence of time impact was determined by 11 hours/week caring or coordinating care for the child by adding together the number of hours reported for these questions: "Do you or other family members provide health care at home for your child? How many hours per week do you or other family members spend providing this kind of care?" and "How many hours per week do you or other family members spend arranging or coordinating your child's care?" Finally, we defined school absenteeism for children 5 years old or older as missing 11 or more days of school as assessed by the following question, "During the past 12 months, about how many days did your child miss school because of illness or injury?"

Any family impact was defined as endorsing work restriction, financial impact, high medical expenses and/or time impact. Missed school was excluded from the any family impact measure as children less than age 5 years were ineligible for this question.

We determined the presence or absence of a medical home based on a standardized algorithm involving five core components of the medical home: (1) a personal doctor or nurse, (2) a usual source of sick and well care, (3) care coordination, (4) family-centered care, and (5) no problems getting referrals when needed (as operationalized by NCHS) (9). Families needed to report meeting the criteria for each core component in order to have a medical home. We also looked at the core components of care coordination and familycentered care separately.

A personal doctor or nurse was determined by an affirmative answer to the question, "Do you have one or more persons you think of as your child's personal doctor or nurse?" A usual source of sick and well care was derived from the questions: "Is there a place that your child USUALLY goes when (he/she) is sick or you need advice about (his/her) health?", and "Is there a place that your child USUALLY goes when (he/she) needs routine preventive care, such as a physical examination or well-child check-up?" The usual source of sick and well care could not be an emergency room.

The presence of care coordination was assessed for respondents with a need for care coordination. Families had to answer usually or always to "During the past 12 months, how often did you get as much help as you wanted with arranging or coordinating your child's care?" Additionally, families had to report being very satisfied to the following question: "Overall, are you very satisfied, somewhat satisfied, somewhat dissatisfied, or very dissatisfied with the communication among your child's doctors and other health care providers?" Finally, for respondents reporting a need to communicate with the child's school, early intervention program, child care providers, vocational education or rehabilitation program, parents had to report they were very satisfied with that communication.

The presence of family-centered care was determined for all children who had a least one doctor visit in the past 12 months. Respondents had to answer always or usually to each question over the past 12 months. The questions were: "How often did your child's doctors 
and other health care providers spend enough time with (him/her)?", "How often did your child's doctors and other health care providers listen carefully to you?", "When your child is seen by doctors or other health care providers, how often are they sensitive to your family's values and customs?", "How often did you get the specific information you needed from your child's doctors and other health care providers?" and "How often did your child's doctors or other health care providers help you feel like a partner in (his/her) care?" If needed, respondents had to indicate that an interpreter was available.

The last component is no difficulty getting needed referrals. Respondents had to indicate that referrals were not a problem in response to the question: "Was getting referrals a big problem, a small problem, or not a problem?"

Covariates included in the analysis include child's age, sex, race, household income, primary language spoken at home, highest education level in the home, total number of adults in the home and health insurance status, as these may influence access to comprehensive care and family impacts. Table I demonstrates how covariates were categorized. Those with no insurance were excluded from the multivariate analysis due to small numbers ( $\mathrm{n}=4$ in children with T1D).

\section{Analytic Approach}

Statistical analysis was performed using SAS callable Sudaan (10.0.1, Research Triangle Park, NC) and the analyses accounted for the complex sample design and included sample weights as per instructions from NCHS (7). Frequencies of categorical variables are presented as percentages. We assessed differences in proportions of categorical variables using chi squared analyses. We modeled the association between family impacts and a medical home, care coordination, or family-centered care with multivariable logistic regression models adjusting for the covariates listed in Table I (with the dependent variable as the family impact measure). We ran separate models with a medical home, care coordination and family-centered care for each family impact measure. Adjusted Odds Ratios (aOR) with $95 \%$ confidence intervals are presented. $\mathrm{P}<.05$ was considered statistically significant.

SAS coding for the dependent family impact variables closely follow operationalized definitions by NCHS developed for the 2001 NSCSHCN (10). However, we broadened the definition of financial impact (see above). Because of increased item non-response for income, datasets provided by NCHS used multiple imputation if needed to estimate FPL as previously described (11). For comparisons of non-CSHCN and the T1D groups, weighted proportions were input manually into Graphpad software (San Diego, CA) in order to accommodate the different sampling weights provided for CSHCN and children without special healthcare needs.

\section{Results}

Of the 40,723 children included in the NSCSHCN dataset, 779 (1.9\%) reported having diabetes and $622(80 \%)$ of those reported being on insulin. After excluding youth with another significant comorbidity ( $\mathrm{n}=39), 583$ children comprised the T1D group. This subsample represents 116,345 US children nationwide with T1D without the comorbidities listed above. There are 39,944 children without diabetes in the CSHCN group who can be generalized to $10,060,039 \mathrm{CSHCN}$ nationwide. In addition, there were 4,945 children without special healthcare needs weighted to represent 60,948,398 children nationwide.

Table I describes the socio-demographic characteristics of the three groups. The T1D group was older and had a higher proportion of white youth, fewer families at the lower end of the 
poverty level, and a greater proportion of parents with more than a high school education. In the T1D group, 50\% reported a medical home, 59\% reported care coordination, and $77 \%$ reported family-centered care.

The three groups had substantial differences in reported family impacts (Table II). Seventyfive percent of families of children with T1D reported at least one of these impacts compared with $45 \%$ in CSHCN and $17 \%$ in children without special healthcare needs. Families of children with T1D were more likely to report work restriction, financial impact, high medical expenses and time impact than families of other CSHCN and families of children without special health care needs.

In families of children with T1D, families of younger children experienced higher levels of family impacts in some, but not all, domains. Families of younger children were more likely to experience time impacts than families of children in the middle and older age ranges (52\% for children $0-5$ years, $30 \%$ for children $6-11$ years and $15 \%$ for children $12-17$ years, $\mathrm{p}=0.006$ ). There was also a significant difference in the percentage of families who reported ever restricting their work ( $46 \%$ for children $0-5$ years, $45 \%$ for children $6-11$ years, and $29 \%$ for children $12-17$ years, $\mathrm{p}=0.04)$. However, there was no difference in the proportion of families who experienced high medical expenses, financial impact, or school absenteeism (among the older 2 groups). Families of children with type 1 diabetes of any age are likely to experience at least one family impact with $87 \%$ of families of children $0-5$ years, $79 \%$ of families of children 6-11 years and 71\% of families of children 12-17 years reporting any family impact.

In bivariate analyses of youth with T1D, a medical home and care coordination were associated with less financial impact and less work restriction (Table III). Family-centered care was not associated with difference in work restriction. The medical home, care coordination, and family-centered care were not associated with high out-of-pocket medical expenses, time impacts, or school absenteeism. The medical home and care coordination, but not family-centered care, were associated with less likelihood of experiencing any family impact.

After adjusting for potential confounders, the medical home and care coordination were associated with less work restriction and less financial impact (Table III). Those with a medical home or care coordination compared with those without were less likely to have work restriction or to have financial impacts. Those with family-centered care were less likely to restrict work hours or to have financial problems. There was no significant association of the medical home, care coordination, or family-centered care with high medical expenses, time impact, or school absenteeism.

\section{Discussion}

This study adds to the growing literature regarding the impact of T1D on parents and families. Children with diabetes have been reported to miss more school than their peers and siblings $(5,6)$. One study found that $31 \%$ of mothers reduced their work or stopped working after their child's diagnosis of T1D (12). Caring for children with T1D is expensive (13) and families bear some of these costs (2). Earlier studies also demonstrate that T1D is time consuming to manage (4). However, the percentages reported here suggest that T1D is even more impactful than many of these earlier studies describe.

An earlier study evaluated the percentage of families with autism spectrum disorder (ASD) experiencing family impacts. Using the same survey and definitions, financial and time impacts in T1D vs. ASD were comparable with $32 \%$ vs. $39 \%$ respectively reporting the condition caused financial problems and $24 \%$ vs. $27 \%$ respectively reporting time impact. 
Fewer families of children with T1D vs. ASD reported work restriction (35\% vs. 57\% respectively) or needing additional income (24\% vs. $35 \%$ respectively). However, more families of children with T1D vs. ASD report high out-of-pocket medical expenses $(41 \%$ vs. $31 \%)(14)$.

Past studies have demonstrated that the medical home, care coordination or family-centered care have been associated with fewer family impacts in other populations of CSHCN. In families of CSHCN overall, the medical home has been associated with fewer financial problems, less need for additional income, and less work restriction (15). Care coordination has also been associated with less missed school, less out of pocket medical expense, less time coordinating care and less work restriction in CSHCN (16). In families of children with ASD, families with a medical home were significantly less likely to experience financial problems, work restriction, time impact, high medical expenses or to require additional income (14).

There was no association of the care delivery variables with time impacts, high medical expenses, or school absenteeism in families of children with T1D. These thresholds were based on MCHB indicators (10) and thus there could be a "floor effect" in the T1D population, for example, from unavoidable copayments. It is also possible that the medical home, care coordination, and family-centered care cannot reduce or eliminate some impacts for families involving expenses, time and school.

The optimal care of children with T1D requires close collaboration between primary care doctors and the diabetes team. A little more than 20 years ago, about half of pediatricians stated that they managed uncomplicated diabetes and about a third said that they shared responsibility with an endocrinologist (17). More recently, about $80 \%$ of youth with T1D reported seeing a diabetes specialist, either a pediatric or adult endocrinologist (18). Many primary care providers and endocrinologists endorse a model of co-management of children with T1D with responsibilities divided according to the expertise of each (19). Within the NSCSHCN, the qualifying questions for the medical home, care coordination, or familycentered care refer to all medical providers, potentially including both primary care providers and specialists. Thus, our analysis applies to a child's primary care experience as well as to the child's diabetes specialist experience.

This study has several limitations. The cross-sectional nature of the data does not allow us to make any determination of causation between the presence of the medical home and fewer family impacts. The associations between the medical home and family impacts could be affected by an unmeasured confounder. Perhaps greater health literacy allows families to pursue practices that fit the medical home model and also allows for decreased family impact of the child's health condition.

The definitions of the medical home, care coordination and family-centered care are based on parent report and developed by the NCHS (9). They do not measure what health care providers believe they are providing in their offices. However, the NSCSHCN 2001 measurement of a medical home (very similar to the NSCSHCN 2005-06) has been assessed to be among the more robust measures of the medical home when compared with three other population-level databases (20).

Our definition of T1D was limited by the survey questions asked. However, the majority of children with diabetes in the US have T1D (21) and this proportion is increased by limiting the sample to children treated with insulin as we did here. In addition, the racial/ethnic distribution of children with insulin-treated diabetes in our sample is characteristic of T1D rather than type 2 diabetes (21). Nonetheless, the family impacts described are likely related 
to the demands of insulin therapy supporting the relevance of studying children with insulintreated diabetes as shown here.

The definition of work restriction was limited to those who had ever stopped or cut down on work because of their child's condition and so did not include those parents who did not work outside of the home at the time of their child's diagnosis and then did not seek employment outside of the home because of their child's health condition. Because of differences in the demographics between the CSHCN and T1D group, it is possible that this circumstance would occur more frequently in families of CSHCN than in families of children with T1D.

The children without special health care needs group provides a frame of reference and emphasizes the substantial proportion of families of children with T1D experiencing impacts. The CSHCN population is a widely studied population that has a wide variety of chronic conditions. The most frequently reported conditions in the NSCSHCN were asthma, allergies and Attention Deficit Hyperactivity Disorder which, in their milder forms, may be less severe than T1D.

T1D differs from other common, chronic diseases in childhood because of the frequency and complexity of management tasks and because of the need for constant vigilance for symptoms of acute hypoglycemia and diabetic ketoacidosis. T1D management requires extensive parent (includes other primary caretakers) education so that parents can perform day-to-day management tasks (22). Over $75 \%$ of children with T1D monitor blood glucose $\geq 4$ times/day and a similar proportion receive $\geq 3$ insulin injections/day or are on an insulin pump (18). Parents and providers must manage the constant risk of acute hypoglycemia and the competing desire for tight glycemic control.

More can be done to mitigate the impacts of T1D on families. In acknowledgement of the substantial time and financial impacts of diabetes on families, the Social Security Administration recently determined that diabetes requiring insulin therapy is considered a qualifying disability for children less than 6 years old (23). However, $30 \%$ of families of children with T1D aged 6-11 years report time impact and 45\% report work restriction, suggesting that the high rates of family impacts continue into the school-aged years.

Employers can and should develop policies to support parents of CSHCN in the workplace. Parents of CSHCN report especially valuing flexible work policies such as the ability to work flexible hours or work from home, childcare options, and flexible options for use of leave time (24); enactment of such policies by employers may allow employees with CSHCN, such as T1D, to continue working and thus to help diminish the financial impact of the child's condition.

This study suggests that optimizing health care delivery through the medical home may diminish the impact of T1D on families. However, 50\% of families of children with T1D did not report a medical home. Providing a medical home to all children with T1D may help to reduce the proportion of families of children with T1D experiencing family impacts.

Additionally, health care providers could expand evening and weekend appointment options to decrease the frequency that parents needs to miss work and children need to miss school for their medical appointments. Email communication options and patient medical portals can help to decrease interruptions to parents' work days and may also decrease the amount of time that parents must spend coordinating their children's care. Improved health insurance options with yearly caps on office visit and prescription co-payments could help to reduce the high out-of-pocket costs of T1D. 
Our data demonstrate that T1D has sizeable impacts, affecting three-quarters of families of youth with T1D, $66 \%$ more than the proportion of families of children with other special health care needs, and 4.4 times more than families of children without special healthcare needs. Our findings also support that the medical home, care coordination, and familycentered care may lessen financial and work-related impacts. Further research is needed to better understand why families of children with T1D experience such frequent impacts and to measure the effects of health care, school, work, and policy interventions to mitigate the impacts. Longitudinal studies aimed at providing care coordination, family-centered care, and the medical home with assessments of family impact can confirm the associations described here. Programs to enhance care delivery to specifically address work, financial, time, and school concerns might be especially beneficial for families of youth with T1D.

\section{Acknowledgments}

M.K. is supported by a Health Resources and Services Administration grant (T32 HP10018) to the Harvard Pediatric Health Services Research Fellowship Program. Any analyses, interpretations, or conclusions are reached by the authors and not the National Center for Health Statistics, which is responsible only for the initial data.

We would like to thank Sowmya R. Rao, PhD, University of Massachusetts Medical School, for providing statistical consultation and Lisa K. Volkening, MA, Joslin Diabetes Center, for her careful review of the manuscript.

\section{Abbreviations}

$\begin{array}{ll}\text { T1D } & \text { Type 1 Diabetes } \\ \text { NSCSHCN } & \text { National Survey of Children with Special Health Care Needs } \\ \text { CSHCN } & \text { Children with special health care needs } \\ \text { NCHS } & \text { National Center for Health Statistics } \\ \text { MCHB } & \text { Maternal and Child Health Bureau } \\ \text { aOR } & \text { adjusted Odds Ratio } \\ \text { FPL } & \text { federal poverty level } \\ \text { ASD } & \text { Autism Spectrum Disorder }\end{array}$

\section{References}

1. Medical Home Initiatives for Children With Special Needs Project Advisory Committee. American Academy of Pediatrics. The medical home. Pediatrics. 2002 Jul.110:184-186. [PubMed: 12093969]

2. Songer TJ, LaPorte R, Lave JR, Dorman JS, Becker DJ. Health insurance and the financial impact of IDDM in families with a child with IDDM. Diabetes Care. 1997 Apr.20:577-584. [PubMed: 9096983]

3. Wood JR, Laffel LM. Technology and intensive management in youth with type 1 diabetes: state of the art. Curr Diab Rep. 2007 Apr.7:104-113. [PubMed: 17425914]

4. Ziaian T, Sawyer MG, Reynolds KE, Carbone JA, Clark JJ, Baghurst PA, et al. Treatment burden and health-related quality of life of children with diabetes, cystic fibrosis and asthma. J Paediatr Child Health. 2006 Oct.42:596-600. [PubMed: 16972965]

5. Glaab LA, Brown R, Daneman D. School attendance in children with Type 1 diabetes. Diabet Med. 2005 Apr.22:421-426. [PubMed: 15787667]

6. Parent KB, Wodrich DL, Hasan KS. Type 1 diabetes mellitus and school: a comparison of patients and healthy siblings. Pediatr Diabetes. 2009 Dec.10:554-562. [PubMed: 19496963] 
7. Blumberg SJ, Welch EM, Chowdhury SR, Upchurch HL, Parker EK, Skalland BJ. Design and operation of the National Survey of Children with Special Health Care Needs, 2005-2006. Vital Health Stat. 2008 Dec.1:1-188.

8. Bethell CD, Read D, Stein RE, Blumberg SJ, Wells N, Newacheck PW. Identifying children with special health care needs: development and evaluation of a short screening instrument. Ambul Pediatr. 2002 Jan-Feb;2:38-48. [PubMed: 11888437]

9. Centers for Disease Control and Prevention. [Accessed February 18, 2011.] Progress Toward Implementing Community-Based Systems of Services for Children with Special Health Care Needs: Summary Tables from the National Survey of Children with Special Health Care Needs, 20052006. 2007. Available at: http://www.cdc.gov/nchs/data/slaits/Summary_tables_NSCSHCN_0506.pdf

10. Child and Adolescent Health Measurement Initiative (CAHMI). National Survey of Children with Special Health Care Needs SAS Codebook, Version 1, 2007. 2001. www.childhealthdata.org

11. Pedlow, S.; Luke, Julian; Blumberg, Stephen J. [Accessed February 18, 2011.] Multiple Imputation of Missing Household Poverty Level Values from the National Survey of Children with special Health Care Needs, 2001 and the National Survey of Children's Health, 2003. 2007. Available at: http://www.cdc.gov/nchs/data/slaits/mimp01_03.pdf

12. Lange K, Danne T, Kordonouri O, Berndt V, Muller B, Schwarz HP, et al. Diabetes in childhood: everyday burden and professional consequences for parents. Dtsch Med Wochenschr. 2004 May 14.129:1130-1134. [PubMed: 15143455]

13. American Diabetes Association. Economic Costs of Diabetes in the U.S. in 2007Authors. Diabetes care. 2007; 31:596-615.

14. Kogan MD, Strickland BB, Blumberg SJ, Singh GK, Perrin JM, van Dyck PC. A national profile of the health care experiences and family impact of autism spectrum disorder among children in the United States, 2005-2006. Pediatrics. 2008 Dec.122:e1149-58. [PubMed: 19047216]

15. Kuhlthau K, Hill KS, Yucel R, Perrin JM. Financial burden for families of children with special health care needs. Matern Child Health J. 2005 Jun.9:207-218. [PubMed: 15965627]

16. Turchi RM, Berhane Z, Bethell C, Pomponio A, Antonelli R, Minkovitz CS. Care coordination for CSHCN: associations with family-provider relations and family/child outcomes. Pediatrics. 2009 Dec.124:S428-34. [PubMed: 19948609]

17. Golden MP, Hibbard RA, Ingersoll GM, Kronz KK, Fineberg NS, Marrero DG. Pediatric endocrinologic recommendations, pediatric practice, and current pediatric training regarding care of children with diabetes. Pediatrics. 1989 Jul.84:138-143. [PubMed: 2740163]

18. Paris CA, Imperatore G, Klingensmith G, Petitti D, Rodriguez B, Anderson AM, et al. Predictors of insulin regimens and impact on outcomes in youth with type 1 diabetes: the SEARCH for Diabetes in Youth study. J Pediatr. 2009 Aug.155:183-9.e1. [PubMed: 19394043]

19. Wegner SE, Lathren CR, Humble CG, Mayer ML, Feaganes J, Stiles AD. A medical home for children with insulin-dependent diabetes: comanagement by primary and subspecialty physicians-convergence and divergence of opinions. Pediatrics. 2008 Aug.122:e383-7. [PubMed: 18676524]

20. Bethell CD, Read D, Brockwood K. American Academy of Pediatrics. Using existing populationbased data sets to measure the American Academy of Pediatrics definition of medical home for all children and children with special health care needs. Pediatrics. 2004 May.113:1529-1537. [PubMed: 15121922]

21. Liese AD, D'Agostino RB Jr, Hamman RF, Kilgo PD, Lawrence JM, et al. SEARCH for Diabetes in Youth Study Group. The burden of diabetes mellitus among US youth: prevalence estimates from the SEARCH for Diabetes in Youth Study. Pediatrics. 2006 Oct.118:1510-1518. [PubMed: 17015542]

22. Silverstein J, Klingensmith G, Copeland K, Plotnick L, Kaufman F, Laffel L, et al. Care of children and adolescents with type 1 diabetes: a statement of the American Diabetes Association. Diabetes Care. 2005 Jan.28:186-212. [PubMed: 15616254]

23. [Accessed August 12, 2011.] Disability Evaluation Under Social Security (Blue Book, 2011). 2011. Available at: http://www.ssa.gov/disability/professionals/bluebook/109.00-Endocrine-Childhood.htm 
24. Perrin JM, Fluet CF, Honberg L, Anderson B, Wells N, Epstein S, et al. Benefits for employees with children with special needs: findings from the collaborative employee benefit study. Health Aff (Millwood). 2007 Jul-Aug;26:1096-1103. [PubMed: 17630452] 


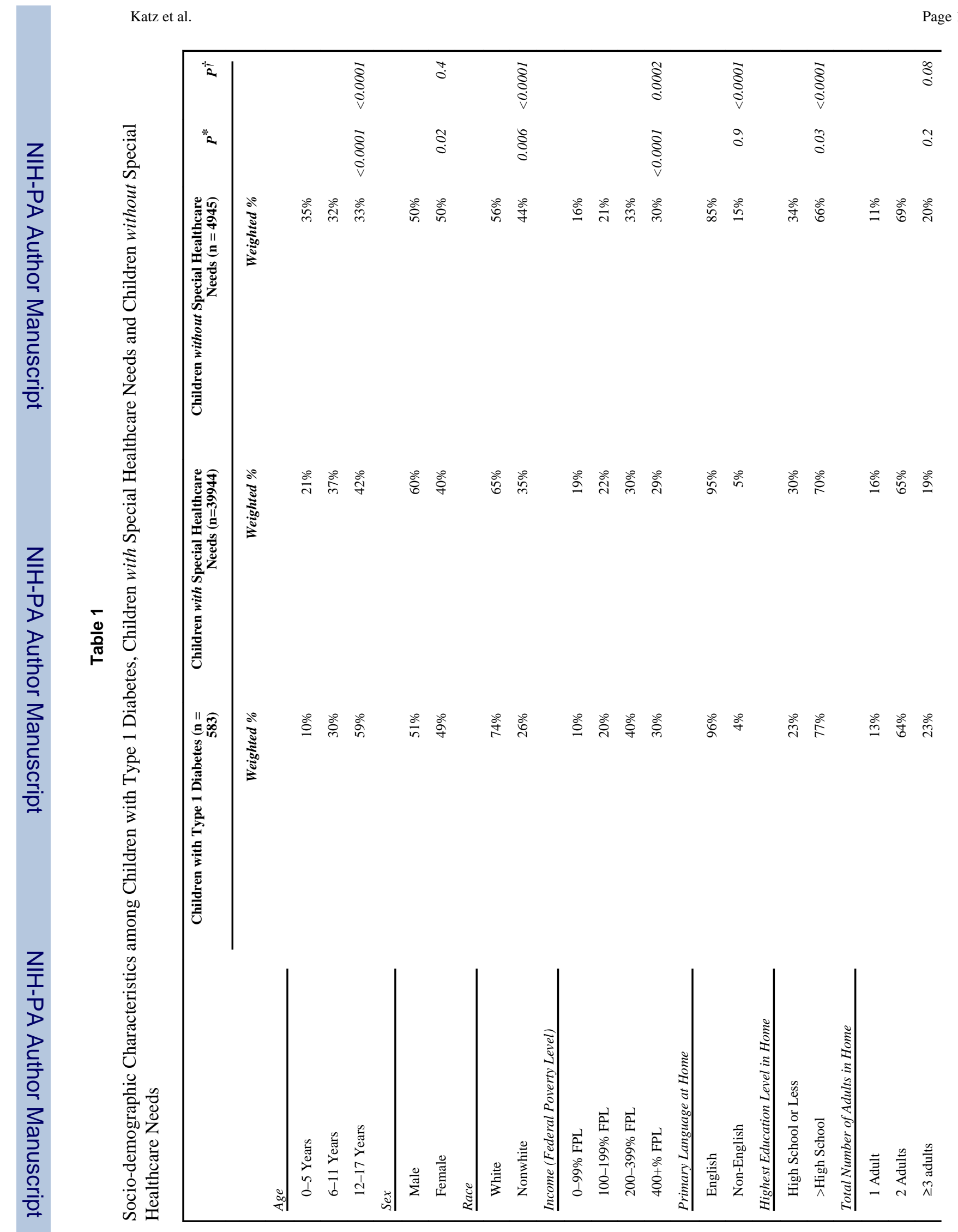

J Pediatr. Author manuscript; available in PMC 2013 May 01. 


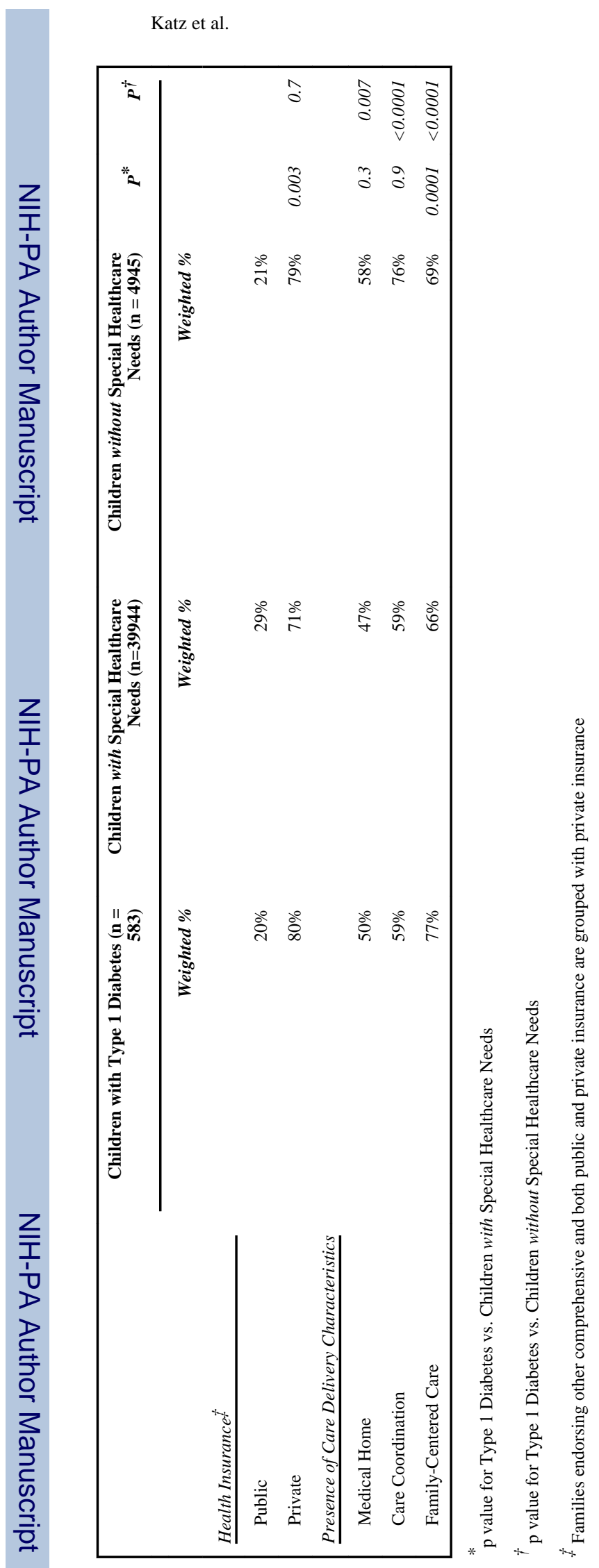

J Pediatr. Author manuscript; available in PMC 2013 May 01. 


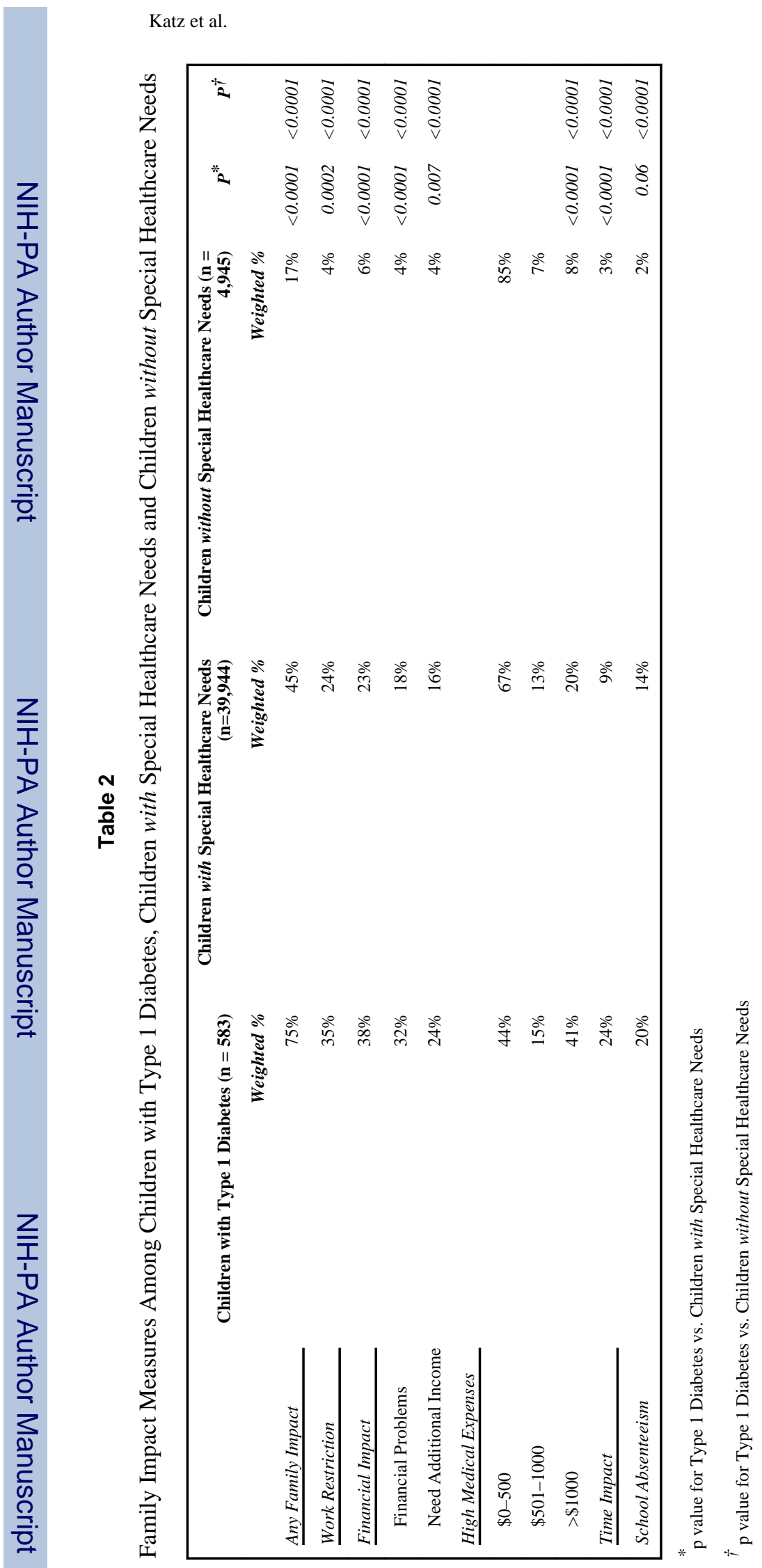

J Pediatr. Author manuscript; available in PMC 2013 May 01. 


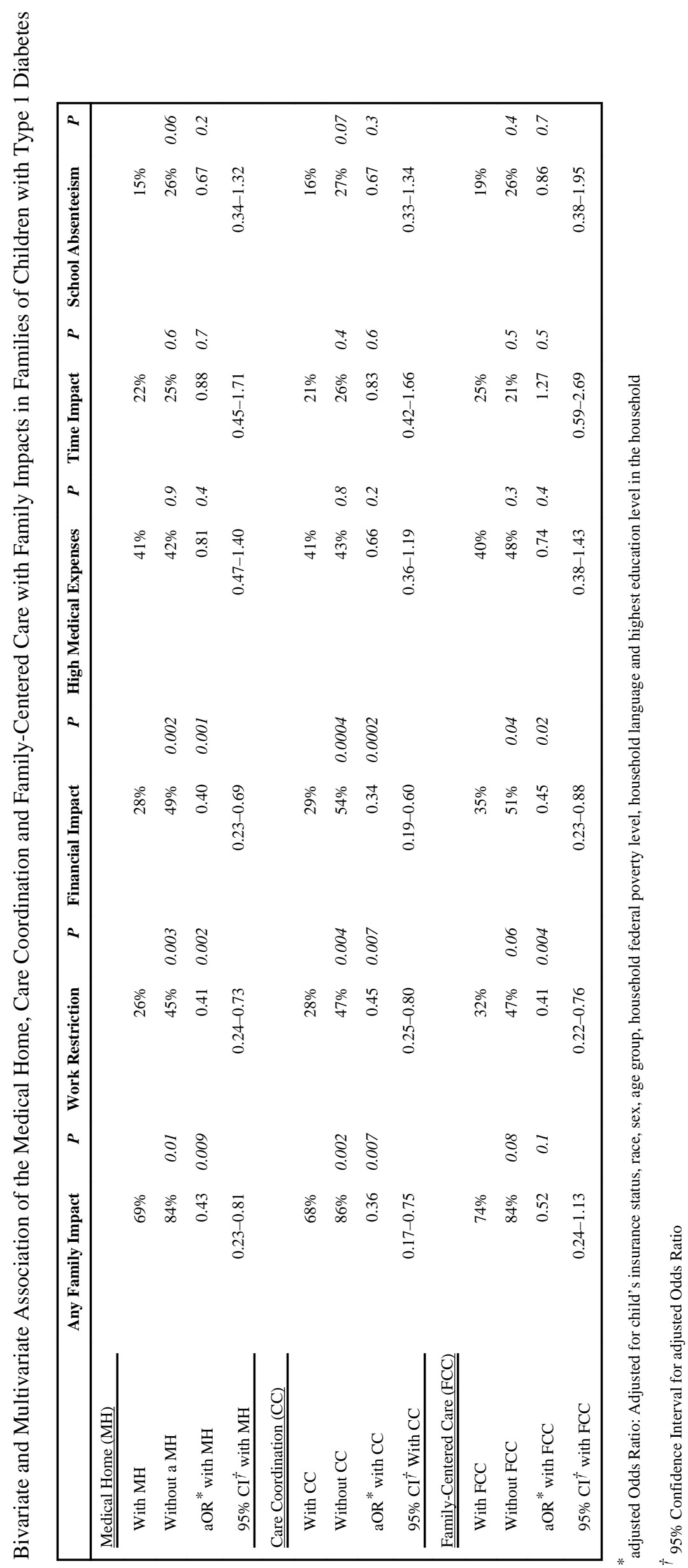

